\title{
The Tribe of Educational Technologies
}

\author{
Abdulrahman Essa Al Lily ${ }^{1}$ \\ ${ }^{1}$ Department of Educational Technologies, King Faisal University, Saudi Arabia \\ Correspondence: Abdulrahman Essa Al Lily, Department of Educational Technologies, King Faisal University, \\ Saudi Arabia. E-mail: allili55@hotmail.com
}

Received: March 13, 2014 Accepted: April 19, 2014 Online Published: May 28, 2014

doi:10.5539/hes.v4n3p19

URL: http://dx.doi.org/10.5539/hes.v4n3p19

\begin{abstract}
This article looks into the claim that the international academic community of educational technologies seems to have functioned in a "tribal" way, having formed themselves around tribe-like patterns. It therefore addresses the research question: What are these claimed tribe-like practices that such a community exhibits? This question is answered qualitatively, examining empirically the habits of three Saudi Arabian Bedouin real tribes, followed by empirical comparison of these tribal habits with the habits of the academic community of educational technologies. Having analysed the data using the grounded theory approach, three key themes emerged: Cultural Similarities between Tribes and Academic Communities; Political Similarities between Tribes and Academic Communities; and Social Similarities between Tribes and Academic Communities. Having considered these themes collectively with reference to the existing literature, a theoretical proposition has been grounded: that academic communities are similar to tribes in the sense that all, naturally, constitute themselves in ethnic groups characterised by distinct cultural, political and social norms. The implication is thus that such communities are, at least partially, culturally, politically and socially different. Echoing such an implication, the recommendation is not to seek to remove such cultural, political and social differences and therefore make them act as one, but rather to foster cross-community cultural, political and social exchange and therefore learning.
\end{abstract}

Keywords: tribe, education, technology, Saudi, anthropology

\section{Introduction and Literature Review}

The editors' introduction to the Learning, Media and Technology Journal (Selwyn, 2012) directed a criticism to the international academic community of educational technologies, accusing them of having performed in a "tribal" way, having arranged themselves around tribe-like patterns. Since this claim seems fundamental, the editors of the Journal should have explained in some depth what they actually mean here by the term "tribe". Given the lack of a deeper explanation, one might thus accuse, at least defensively, these editors of using fancy terms with no reflexive attention to their social, cultural and political ramifications. Adams (1976) dedicated a column to such a matter, publishing a book called The Academic Tribes. This was followed by another publication by Becher and Trowler (2001) called Academic Tribes and Territories, enquiring into "the numerous and subtle boundaries within the world of scholarly enquiry" (p. i). Two years ago, Trowler and colleagues (2012) published a book entitled Tribes and Territories in the 21st Century, addressing a variety of issues across disciplines and among academic communities. Despite the significance of these publications, the authors, however, appear to have mostly taken the term "tribe" at face value, using it for the most part as merely a synonym for "social group," "social community" or "certain culture.” More essentially, these publications seem to show limited empirical understanding of tribal configurations. Considering these limitations, a call can be made for further research intended to first empirically highlight the practices of real tribes and then empirically compare these tribal practices with the practices of academic communities. The current article therefore takes this initiative, examining empirically the habits of three Saudi Arabian Bedouin actual tribes and comparing again empirically these tribal habits with the habits of the academic community of educational technologies.

The traditional practices of real tribes, be they for example Arab, Indian, Chinese or African, are well documented through publications on their novels, poems, educational ideas, transitions and anthropological aspects (see for example Tutchin, 1691; Gutkind, 1970; Marshall \& Pope, 1873; Caton, 1990; Langloh-Parker, 1905; Cook, 1934; Pompei et al., 1990; Gluckman, 2007; Kornel, 2006; Lowe et al., 1997; Husni, 2013). Some literature moreover sees the term "tribe" as a theoretical concept, arguing that, if a community exhibits certain tribe-like practices, it can thus be theoretically classified as "tribalistic." Hence, some researchers have used the 
word "tribe" as an ideology (i.e., tribalism), as a verb (i.e., tribalise), as an adjective (i.e., tribalist or tribalistic) and moreover as a social movement (i.e., the New Tribalism) (see McLuhan, 1970, 1994; Beteille, 1980; James, 2006; Horsman \& Marshall, 1994; Vail, 1989; Mafeje, 1971; Gluckman, 1960; Hunter, 1994; Frohnmayer, 1988). Adams and Smith (2008) theorise the ability of offline tribal practices to influence online practices, investigating what they call "e-tribes," looking at the tribal nature of online environments (see also Samin, 2008). Thus, it is palatable to, as it is the case in the current investigation, view "tribe" as a theoretical concept, thereby examining the extent to which the academic community of educational technologies scholars has "gone tribalistic."

\section{Methodology}

\subsection{Method of Enquiry}

Arguably, any employed academic belongs to at least two "institutions." One is the establishment by which one is employed, whereas the other is the international academic community with which one is associated. By way of illustration, although I am employed by an institution called King Faisal University, I am, at the same time, associated with the international academic community of educational technologies scholars. Thus, each employed academic has two "workplaces." One is physical, being the workplace in the establishment by which one is employed. The other workplace is imaginary, i.e., the hypothetical loose intellectual domain within which one works. These two workplaces should consequently become equally subjected by the employed academic to academic investigation through action research. In action research, one researches the institution with which one is concerned (Herr \& Anderson, 2005), and therefore employed academics are encouraged to, the author argues, conduct action research not only on the institution by which they are employed, but moreover on the hypothetical international academic community with which they are associated. Following this argument, the author in the current study conducted action research on the academic community (i.e., the community of educational technologies scholars) with which he was involved, seeking to highlight tribe-like practices that this community exhibited.

However, academic communities are essentially "institutions," and institutions are inherently political and have politics which will unavoidably be encountered by action researchers studying their academic community (Herr \& Anderson, 2005). Action researchers, who are keen to take a questioning stance, will more likely find themselves swimming "against the current," clashing with these politics. Action researchers who seek to challenge the theories set up by other members of their academic community cannot be expected to end up being liked or even accepted by their peers. Such action researchers are encouraged to challenge their own academic community; yet the ability of anyone to challenge his/her own community must be weak, considering that s/he is an insider in relation to this community and therefore is likely to take the surroundings for granted. In order for action researchers to avoid taking the surroundings for granted, they should thus research their own communities in collaboration with other action researchers from other communities (Herr \& Anderson, 2005) and should read the literature produced by these other academic communities (Selwyn, 2012). Academics are normally educated within a certain academic community (i.e., within a certain intellectual domain), thus likely taking "ready-made" academic values and norms as an unquestioned and unquestionable guide for all situations arising within the academic societal world (Schütz, 1944; Al Lily, 2012). Such values, handed down to subjects by the academic authorities, carry their evidence within themselves and are likely to be taken for granted until evidence to the contrary emerges (Schütz, 1944; Al Lily, 2012). Such evidence can be realised through reading others' literatures, attending others' academic events, becoming involved with others' networks and collaborating with members of other academic communities. The awareness of such evidence can therefore interrupt the flow of habit and can even lead in turn to "perspective transformation" (Mezirow, 1990, 1991; Schütz, 1944; Al Salem, 2005). Keeping this in mind then, the current study is informed by my readings of others' literatures, my attendance of others' academic events, my involvement with others' networks and my academic and social collaboration with members of other academic communities.

\subsection{Research Question}

The current study was conducted as part of the author's research activity as a member of the international academic community of educational technologies. It, in other words, is carried out as part of his own action research cycle, reflecting his concern to address the issues related to the academic community with which he is associated. It, as mentioned earlier, addresses the research question: What are the claimed tribe-like practices that the academic community of educational technologies exhibits? In order to address such a question, the study shall first investigate the cultural patterns of the so-called "tribe" and, likewise, the cultural patterns of the so-called "academic communities." Then, the study shall cross reference the patterns of tribes and the patterns of academic communities, thus highlighting the similarities and points of departure between them. The study will 
eventually draw out some conclusions on just how tribal academic communities have actually been.

\subsection{Data Collection}

The current study was conducted in 2012 to 2013. Its main focuses were, as mentioned previously, the cultural patterns of tribes and the cultural patterns of academic communities. In order to collect data on the cultural patterns of tribes, the author did reading in anthropology, carried out an unstructured observation of three Saudi Arabian Bedouin real tribes over a year, conducted unstructured individual interviews with two subjects of each real tribe and carried out one unstructured focus group that contains one subject of each tribe. In order to collect data concerning the cultural patterns of the academic community of educational technologies, the author analysed its literatures and did an unstructured observation of its research dynamics through its academic events, conferences and seminars in America, the UK, Italy, Bulgaria, Japan, Malaysia and Saudi Arabia. In addition, the author conducted one unstructured focus group that consisted of three subjects from the international academic community, American, English and Saudi. This is in addition to unstructured interviews with thirteen researchers and practitioners from the international academic community of educational technologies, besides a linguistic researcher, a historical researcher, an economic researcher and a researcher with a mathematics background. A key reason for including subjects from other academic communities is that it is believed by Herr and Anderson (2005) to be good practice if action researchers research their own community in collaboration with outsiders, i.e., researchers from communities other than theirs. The academic participants in the study come from the five main continents in the world. A strength in this study is its idea of looking at actual tribes and academics.

\subsection{Data Analysis}

The data collected were analysed along the lines of the grounded theory method, following the process suggested by Glaser and Strauss (1967): Data $\rightarrow$ Code $\rightarrow$ Category $\rightarrow$ Theme $\rightarrow$ Theory. Once the data were collected, the author repeatedly went through them in an attempt to find "natural analytical divisions" (Holliday, 2005: 105), bearing the research question in mind throughout. Once these natural analytical divisions were identified, the author began to code the data with them in mind, generating codes. He subsequently assembled similar codes to create categories, which he grouped in turn to form themes and ultimately to constitute a theoretical proposition. In this approach, the data "are taken as a whole and then organised according to themes, but the themes themselves are partly emergent and partly influenced by [the research question] that the researcher brought to the research" (Holliday, 2005, p. 108). The thematic process here was therefore iterative, as the author repeatedly followed the analytical steps back and forth, in an attempt to make better sense of the whole structure (Denscombe, 2007). The data were analysed with the intention of highlighting the tribe-like practices that the international academic culture of educational technologies was claimed to exhibit. The table below shows the data after sorting. 
Table 1. The data after being sorted using the grounded theory approach (NB the unreadable text in the table will be enlarged and made readable later when discussing the findings)
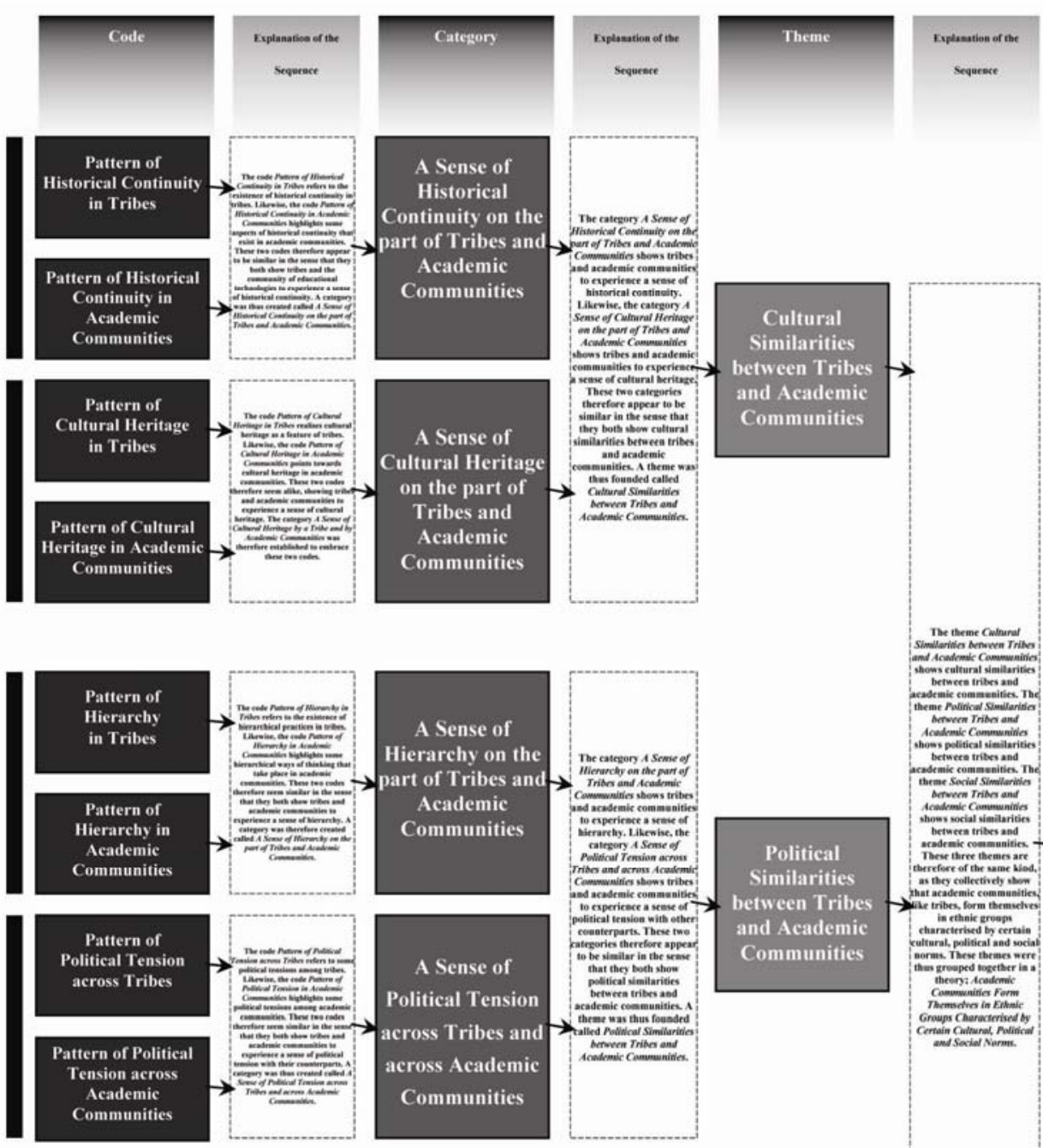

Pattern of Political Tension across Tribes
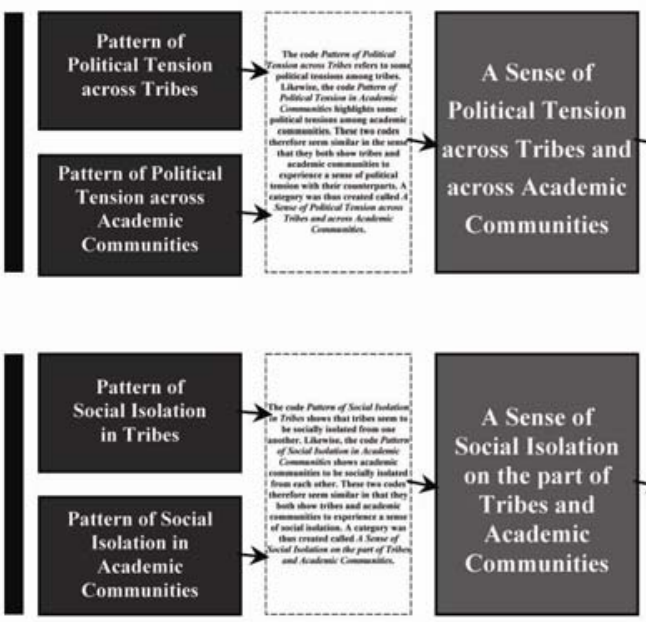

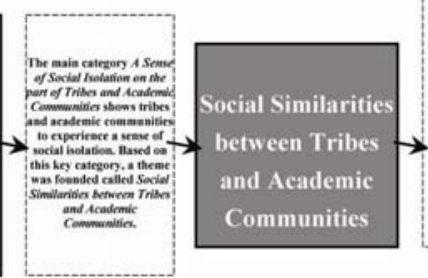




\section{Findings and Discussions}

Analysis of the collected raw data pointed to three key themes: Cultural Similarities between Tribes and Academic Communities, Political Similarities between Tribes and Academic Communities and Social Similarities between Tribes and Academic Communities. A reader might feel that looking for similarities right from the start is a source of concern and that one cannot learn about what it is not similar when only similarities have been sought out. Although such concern sounds fair, the aim of this study is to look into similarities alone and leave dissimilarities for further research. Thus, further research is needed that looks at the differences between tribes and academic communities and therefore challenges the findings of the present research. Thus, the current research displays only one side of the coin and thus is in need of another research initiative intended to display the other side. What follows unpacks and discusses the abovementioned themes, showing how these themes were generated from various categories.

\subsection{Cultural Similarities between Tribes and Academic Communities (Theme)}

The current theme Cultural Similarities between Tribes and Academic Communities stemmed, as illustrated in the table below, from two categories: A Sense of Historical Continuity on the part of Tribes and Academic Communities and A Sense of Cultural Heritage on the part of Tribes and Academic Communities. These categories, each of which consists of similar codes, are discussed below.

Table 2. Cultural similarities between tribes and academic communities (theme)

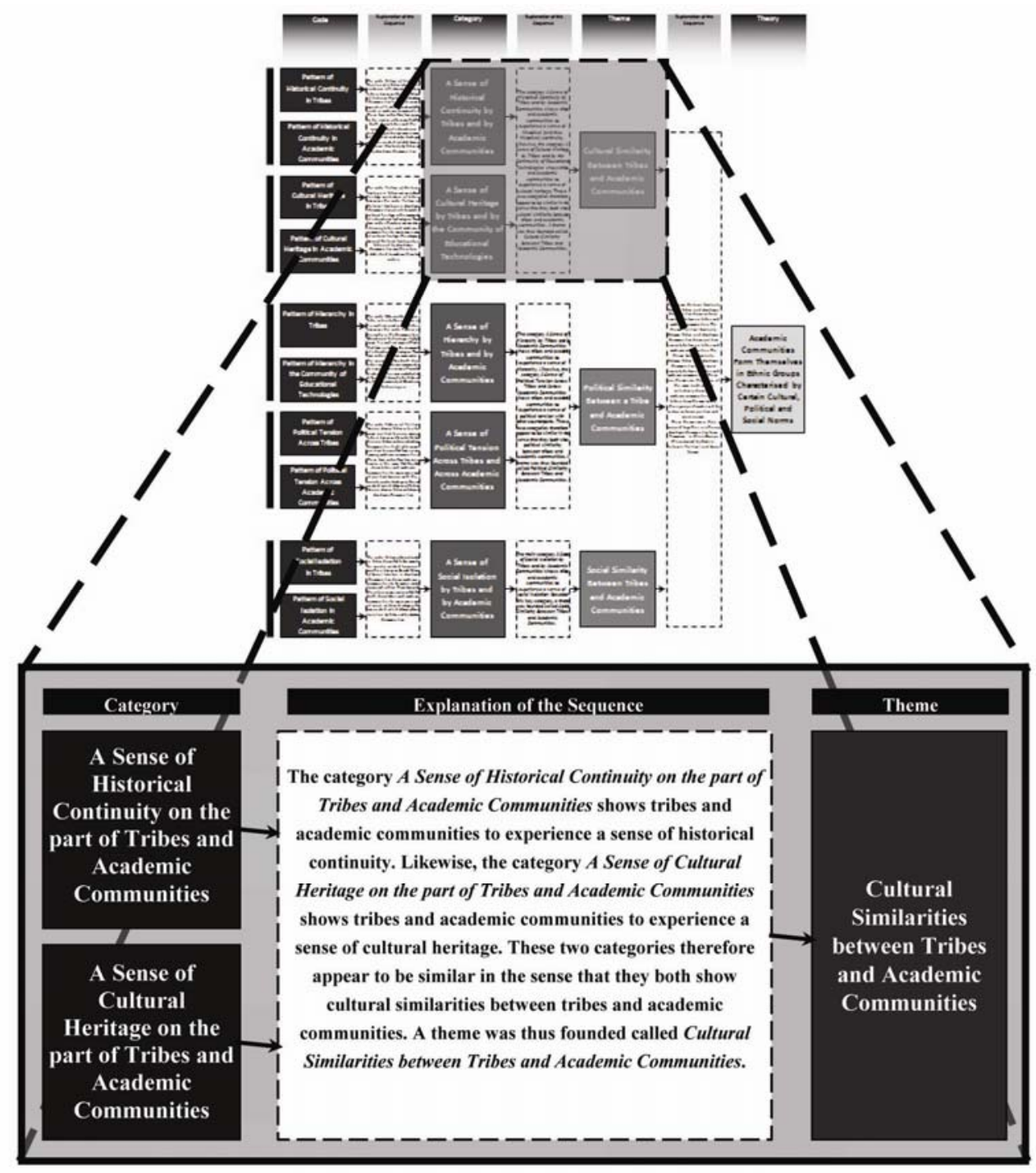




\subsubsection{A Sense of Historical Continuity on the Part of Tribes and Academic Communities (Category)}

This category emerged from two similar codes: Pattern of Historical Continuity in Tribes and Pattern of Historical Continuity in Academic Communities (see Table 3 below). These two codes are discussed in some depth below.

Table 3. A sense of historical continuity on the part of tribes and academic communities (category)

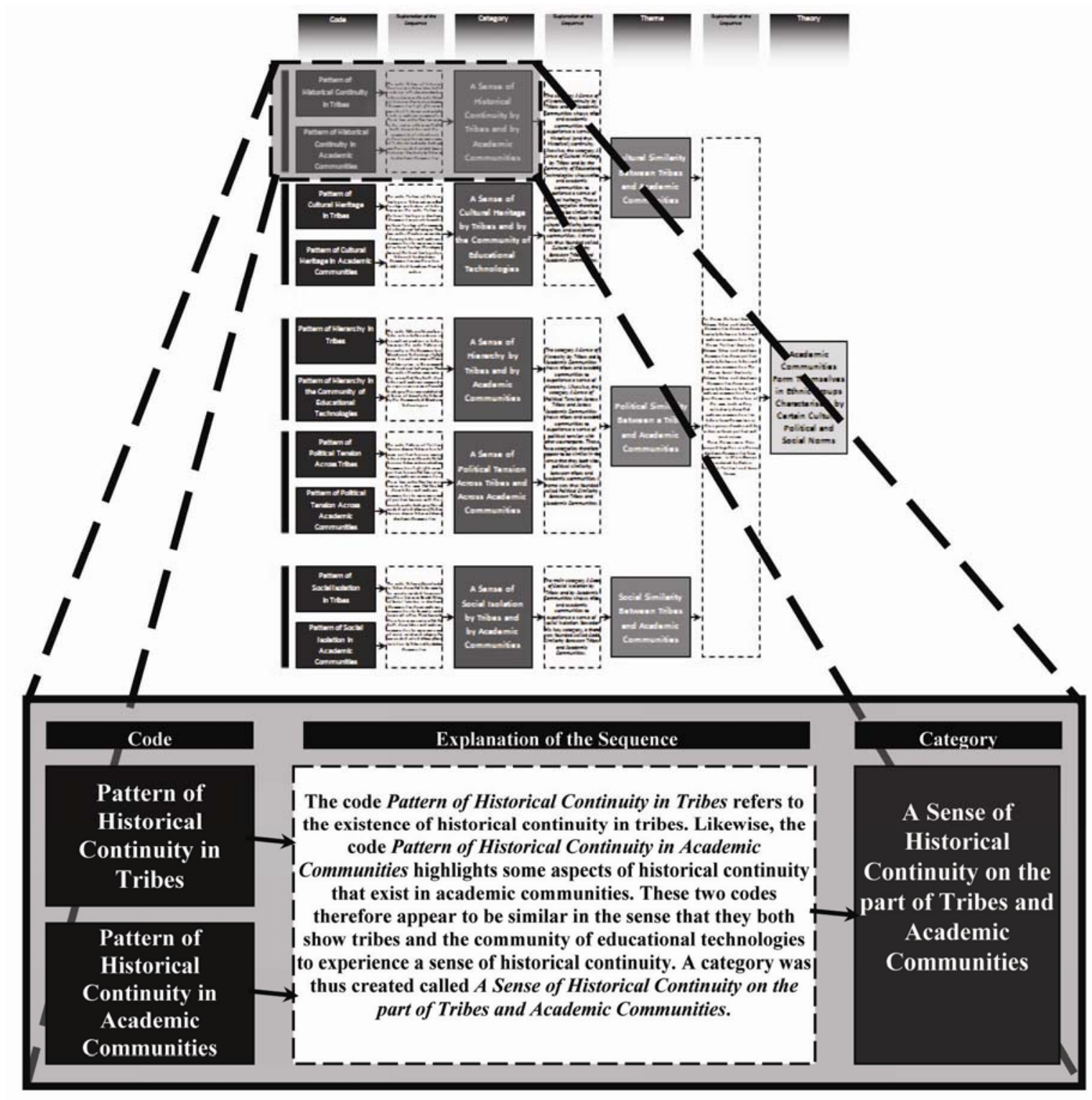

Having observed the three tribes, it appears that, in tribes, there is a sense of stable historical continuity in norms and values. Some of the interviewees report noticing such a sense of stable historical continuity in the academic culture of educational technologies too. The interviewees explain that publications in this field intensively reference former publications, which suggests not only stable historical continuity but moreover limited creative approaches. In conferences the author attended, some of the keynote speeches of full professors were about old theories (e.g., transformative learning theory), representing a common case of how many academics function in such a "circle," merely keeping repeating old theoretical approaches (in this case transformative learning theory, which can be traced back to the 1970s; Mezirow, 1975). Some participants in these conferences that the author interviewed during breaks agree that, although one of the keynote speakers promotes transformative learning theory which encourages emancipation from the mindless and unquestionable acceptance of the social and 
cultural "surroundings", s/he, however, appears not to have shown here an ability to emancipate himself/herself from "surrounding" old theoretical approaches. This could be seen to lend support to the claim that, although academics are perceived as authorities who are associated with the production of knowledge and from whom expertise is sought, they, however, seem to be weak in applying this knowledge to themselves and to their continuing personal and professional development (Hammond et al., 1992; Cornford \& Pollock, 2003). Full professors, one can suggest, are encouraged to act as true leading authorities with the ability to "emancipate" themselves from surrounding pre-existing and pre-developed theoretical structures.

Some interviewees add another (yet similar) point showing the historical continuity of educational technologies. They say that many researchers appear to do their studies and write their publications in a way that reinforces and is in line with existing structures and configurations, rather than pushing current boundaries and destabilising existing structures. This claim by these interviewees appears to be supported by the literature, which records that, because of the stable historical continuity of educational technologies, the teaching and learning structure and infrastructure of the higher education system as a global concept is "one of the most stable institutions in our civilization, surviving for a millennium through wars and plagues and technological change with its values and roles largely intact” (Duderstadt et al., 2002, p. 1). Thus, although newly designed educational technologies are commonplace, they are constructed in a way that merely serves as a complement to existing instructional tools, i.e., "in a way that only gradually is stretching traditional on-campus practices" (Collis \& van der Wende, 2002, p. 62). Thus, the recommendation is that, if the international academic culture of educational technologies would like to avoid being labelled as a tribal unit, its researchers and commentators should consider methodological approaches that promote historical discontinuity, seeking to "knock down" rather than pass on pre-existing rules, resources and theories. A methodological approach that seems an appropriate candidate here is deconstructive postmodernism, which campaigns for the notion of historical discontinuity (cf. Bauman, 1988; Appignanesi \& Garratt, 1995).

\subsubsection{A Sense of Cultural Heritage on the Part of Tribes and Academic Communities (Category)}

The category A Sense of Cultural Heritage on the part of Tribes and Academic Communities is composed of the following two codes: Pattern of Cultural Heritage in Tribes and Pattern of Cultural Heritage in Academic Communities. 
Table 4. A sense of cultural heritage on the part of tribes and academic communities (category)

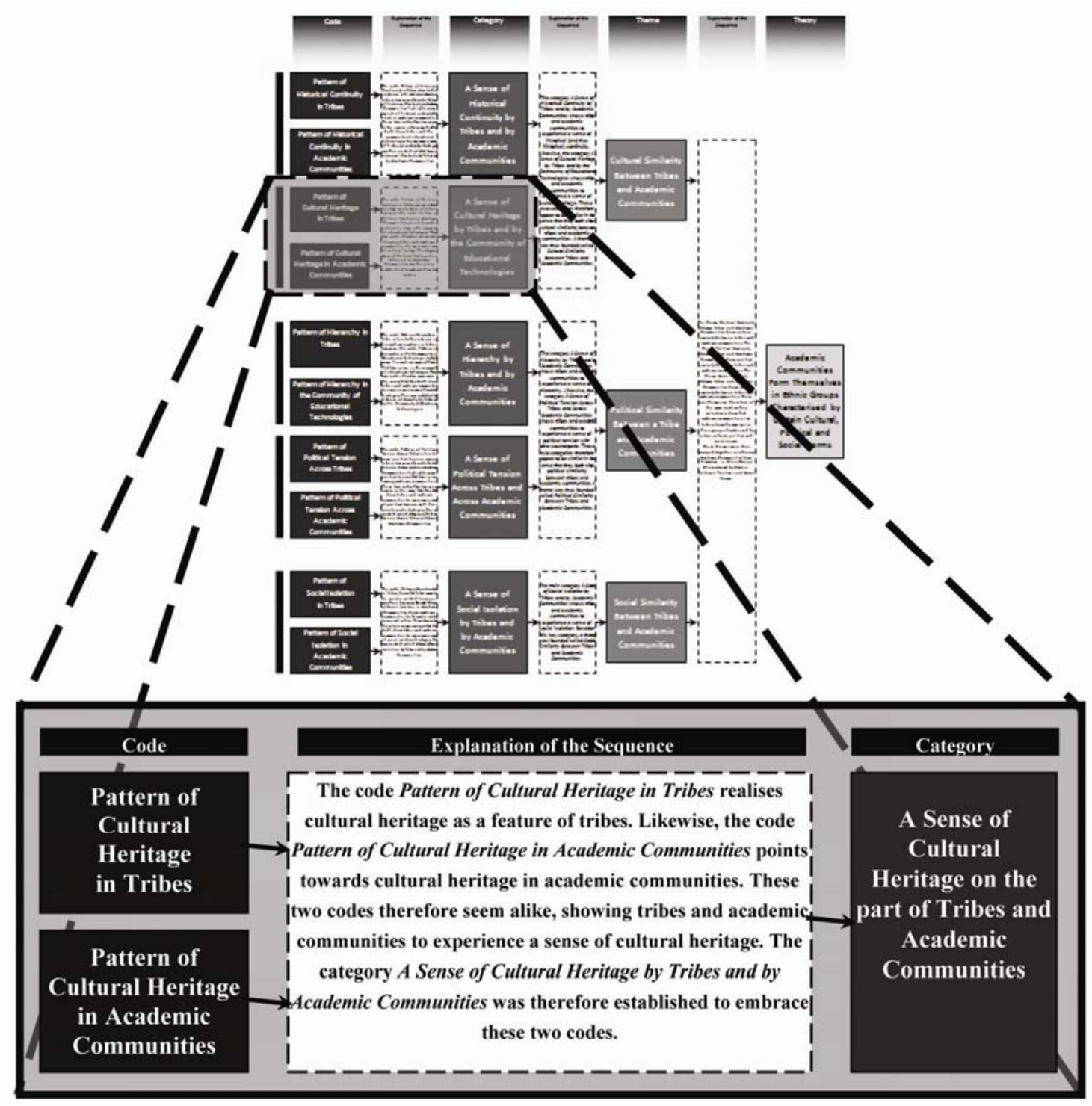

Based on the observation of the three tribes, it seems sensible to contend that a tribe typically sustains a sense of common cultural heritage, shared ancestry and mutual history. Some academic interviewees have shown such a sense of cultural heritage, shared ancestry and history to have existed in the international academic culture of educational technologies via the process of technological reproduction. The literature actually acknowledges this process of technological reproduction. That is, following the classical Marxist notion of reproduction, every social process of production is essentially a process of reproduction (Dear \& Wolch, 1989). This notion seems to have a variety of implications for the field of educational technologies.

One implication is that any process of production is a procedure that entails not only producing substance (here, educational artefacts and software) but also continually reproducing the associated social relations. An additional implication is that newly constructed educational technologies are influenced by previous such technologies, which refers to the "technological shaping of technologies" (see Graça, 2010). Thus, the notion of reproduction implies much more than the mere replication of pre-existing production processes. Reproduction involves various types of historical continuity in social relations during periods of transition (Dear \& Wolch, 1989), and hence the production of educational technologies, as mentioned earlier, needs to take on a deconstructive post-modernistic perspective so as to promote discontinuity in social relations during times of transition. Thus, educational technology is a matter of history and is therefore political, with power relationships between previous generations and following generations. Such historical continuity, according to some interviewees, 
could be said to exist either because following generations intentionally and politically want their past to continue or because following generations just naively let their past continue to exist and frame their own lives, "embracing the past without doing anything about it" (in the words of an interviewee). An interviewee felt obligated to follow previous generations of academics: "we have to speak the language," he complained. Another interviewee thought that each academic community had a certain "mainstream worldview" (in his words) specific to this community, thus existing as a tribe of "like-minded people" (to borrow a phrase from Adams and Smith, 2008, p. 2).

\subsection{Political Similarities between Tribes and Academic Communities (Theme)}

This second theme, labelled Political Similarities between Tribes and Academic Communities, resulted, as illustrated in the table below, from two categories, namely A Sense of Hierarchy on the part of Tribes and Academic Communities and A Sense of Political Tension across Tribes and across Academic Communities.

Table 5. Political similarities between tribes and academic communities (theme)

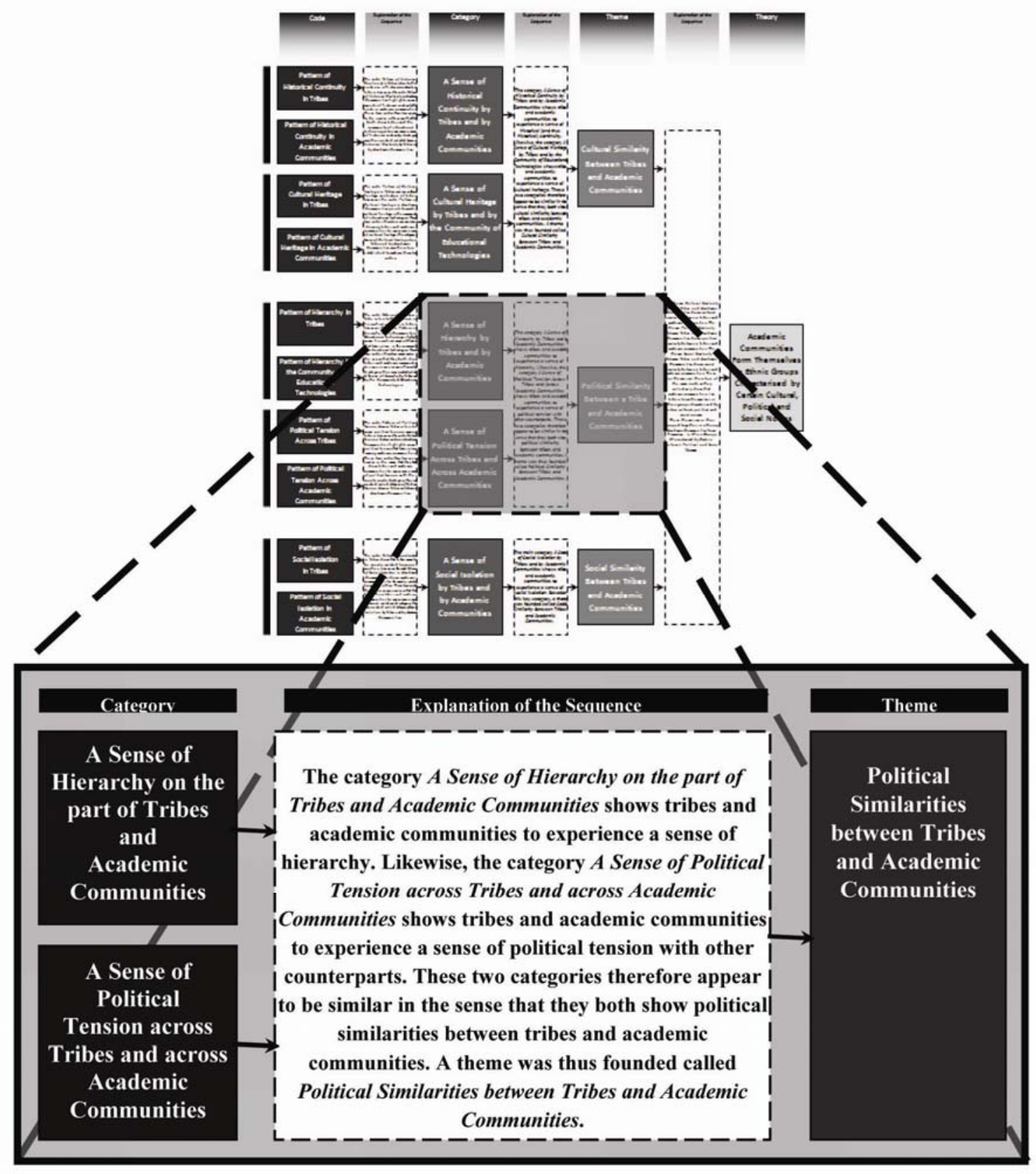


3.2.1 A Sense of Hierarchy on the Part of Tribes and Academic Communities (Category)

This category covers two related codes, which are discussed below.

Table 6. A sense of hierarchy on the part of tribes and academic communities (category)

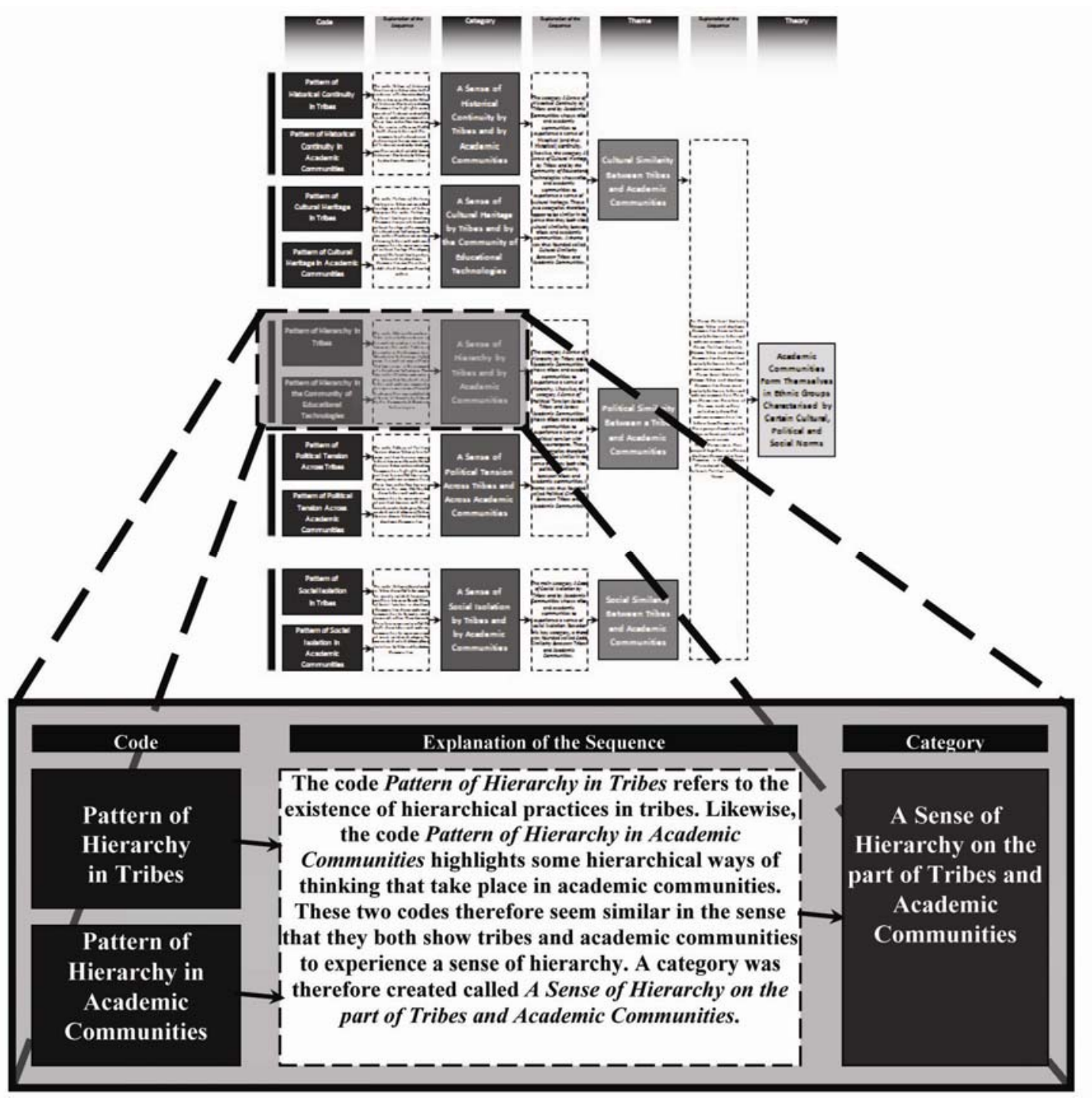

According to what was observed, tribes are understood to display a sense of cultural isolation, with a minimum of social interconnection and cultural exchange across tribes. Some interviewees concur that such a sense of cultural isolation seems to have existed within the academic culture of educational technologies, with weak interdisciplinary connections between the field of educational technologies and other fields. The interviewees concur with those writers (e.g., Apple, 2004; Monahan, 2004; Hope, 2007; McPherson \& Whitworth, 2008; Selwyn, 2010), who criticise the academic community of educational technologies for concentrating predominantly on the educational and technological aspects of educational technologies, thus undermining their cultural, societal, political and economic aspects. Nevertheless, this community might defend themselves, arguing that anthropology, sociology, politics and economy are not their expertise and thus beyond their comfort zone. Researchers on human geography believe that human behaviour is expressed through a complicated set of social, cultural, political and economic processes which characterise every society to some degree, and that time and space define the two dimensions of a fabric upon which the processes of human existence are inscribed (Dear \& Wolch, 1989). Such researchers thus seek to understand the simultaneity of social, cultural, political and economic life in time and space. Researchers on educational technologies should, in the same way, seek to play, 
at least temporarily, this role of human geography researchers, attempting to grasp the simultaneity of the social, cultural, political and economic components of such technologies in time and space.

\subsubsection{A Sense of Political Tension across Tribes and across Academic Communities (Category)}

This category, as shown in the table below, springs from the meeting of two similar codes: Pattern of Political Tension across Tribes and Pattern of Political Tension across Academic Communities.

Table 7. A sense of political tension across tribes and across academic communities (category)

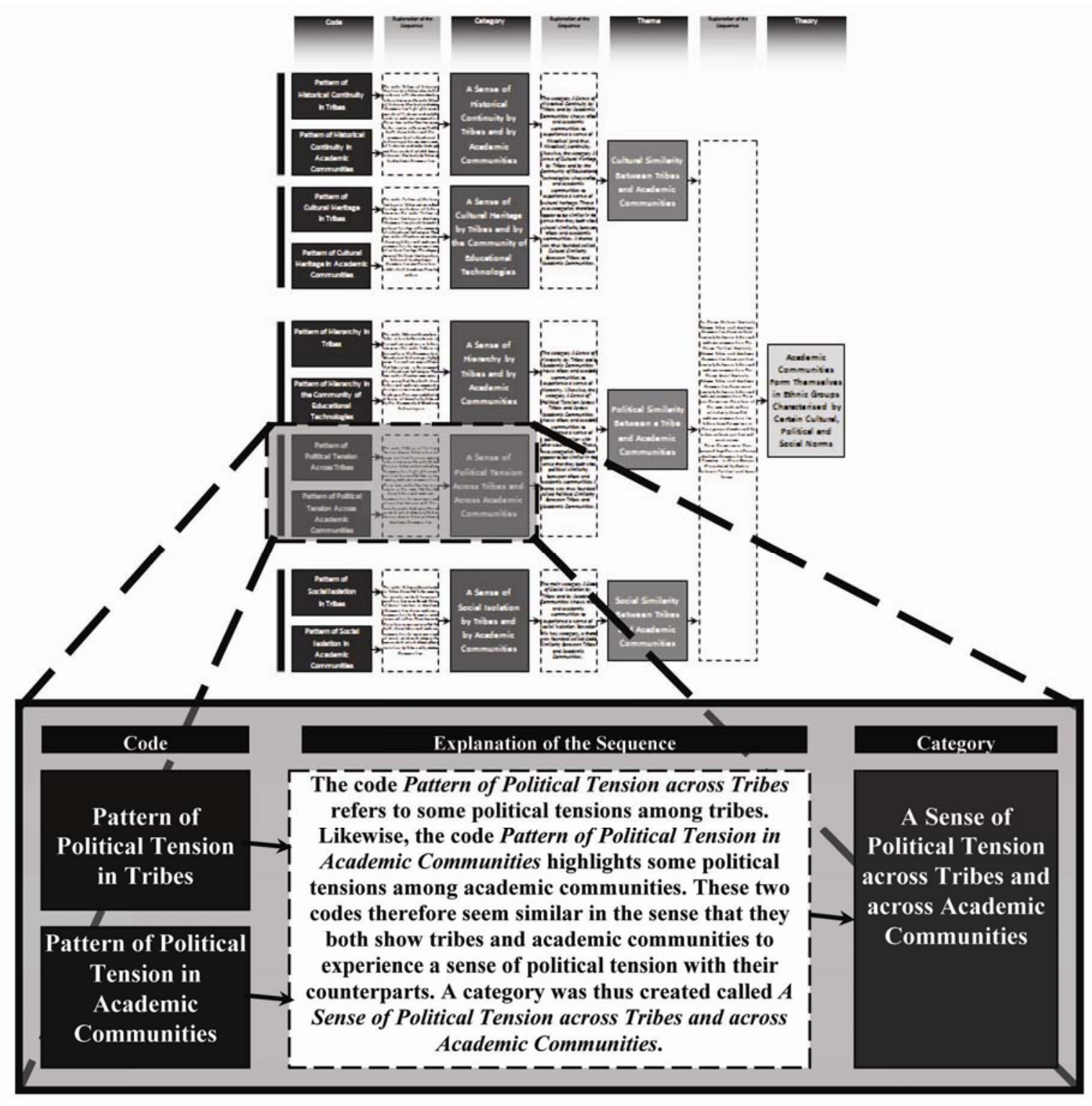

Derived from the author's observational experience with the three tribes, it is apparent that a tribe typically puts on show a sense of hierarchy, upholding hierarchical organisations with "the sheikh" being at the top of the hierarchy. Some academic interviewees have shown such a sense of hierarchy to have existed in the academic culture of educational technologies too, with "the transferability of conclusions derived from the study of an elite group” (Becher \& Trowler, 2001). Anyone examining carefully the literature on educational technologies can notice the existence of certain figures who sometimes appear to lead the rest of scholars within the field, which makes one think of an imaginary green field (i.e., the domain of educational technologies) where there are sheepherders (leading scholars) and sheep (led scholars). The academic culture of educational technologies could, 
moreover, be perceived somehow as a "Bedouin culture" (in the words of an interviewee) wherein the main concern of its members is to search for water (here, academic information), moving from one place to another (here, moving from a library to another and from an academic to another). Yet one negative side of living in a Bedouin culture, the interviewee remarks, is the tension between the sheepherders (here, leading researchers) and sheep (i.e., led researchers).

Hence, one might encourage led and young scholars to deliberately challenge leading and old scholars, echoing the belief that academic innovation and transformation, just like organisational innovation and transformation, may in the final reckoning come up from the bottom, in just the same way that they come down from the top (McPherson \& Whitworth, 2008). Such behaviour on the part of led and young scholars may result in political conflict and tension, which, however, could be seen as a way of fostering creativity within the academic culture of educational technologies, bringing about a variety of novel approaches and new ways of thinking. This gives some credence to Kast's and Rosenzweig's belief in "the constructive and positive role of conflict in fostering creativity and innovation” (1979, p. 301). These two writers, moreover, see some friction between members as “a condition for the generation of fresh ideas” (Kast \& Rosenzweig, 1979, p. 301).

\subsection{Social Similarities between Tribes and Academic Communities (Theme)}

This last theme (Social Similarities between Tribes and Academic Communities), consists of just one main category: A Sense of Social Isolation on the part of Tribes and Academic Communities.

Table 8. Social similarities between tribes and academic communities (theme)

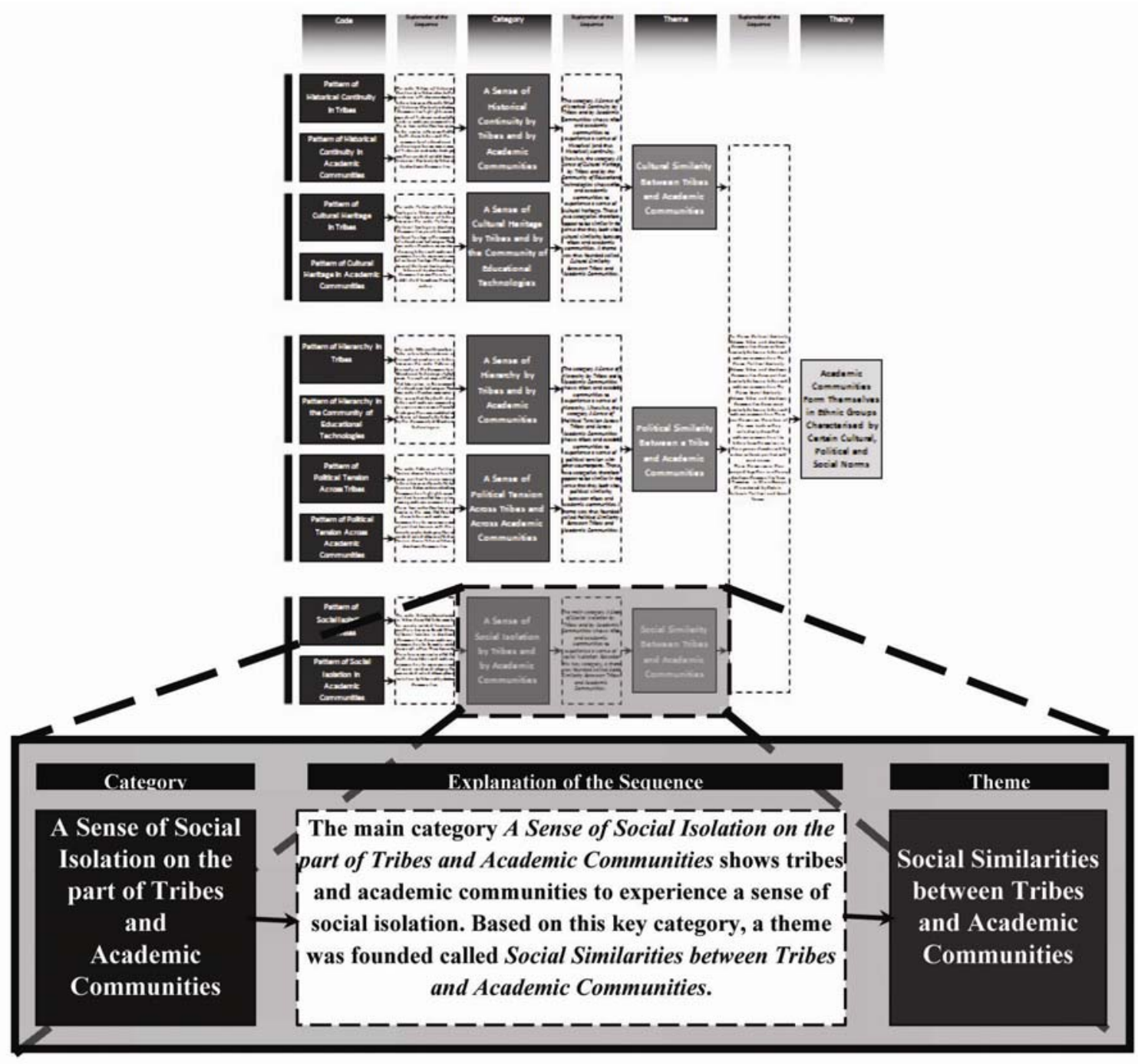




\subsubsection{A Sense of Social Isolation on the Part of Tribes and Academic Communities (Category)}

The category A Sense of Social Isolation on the part of Tribes and Academic Communities arises, as shown in the table below, from two similar codes: Pattern of Social Isolation in Tribes and Pattern of Social Isolation in Academic Communities.

Table 9. A sense of social isolation on the part of tribes and academic communities (category)

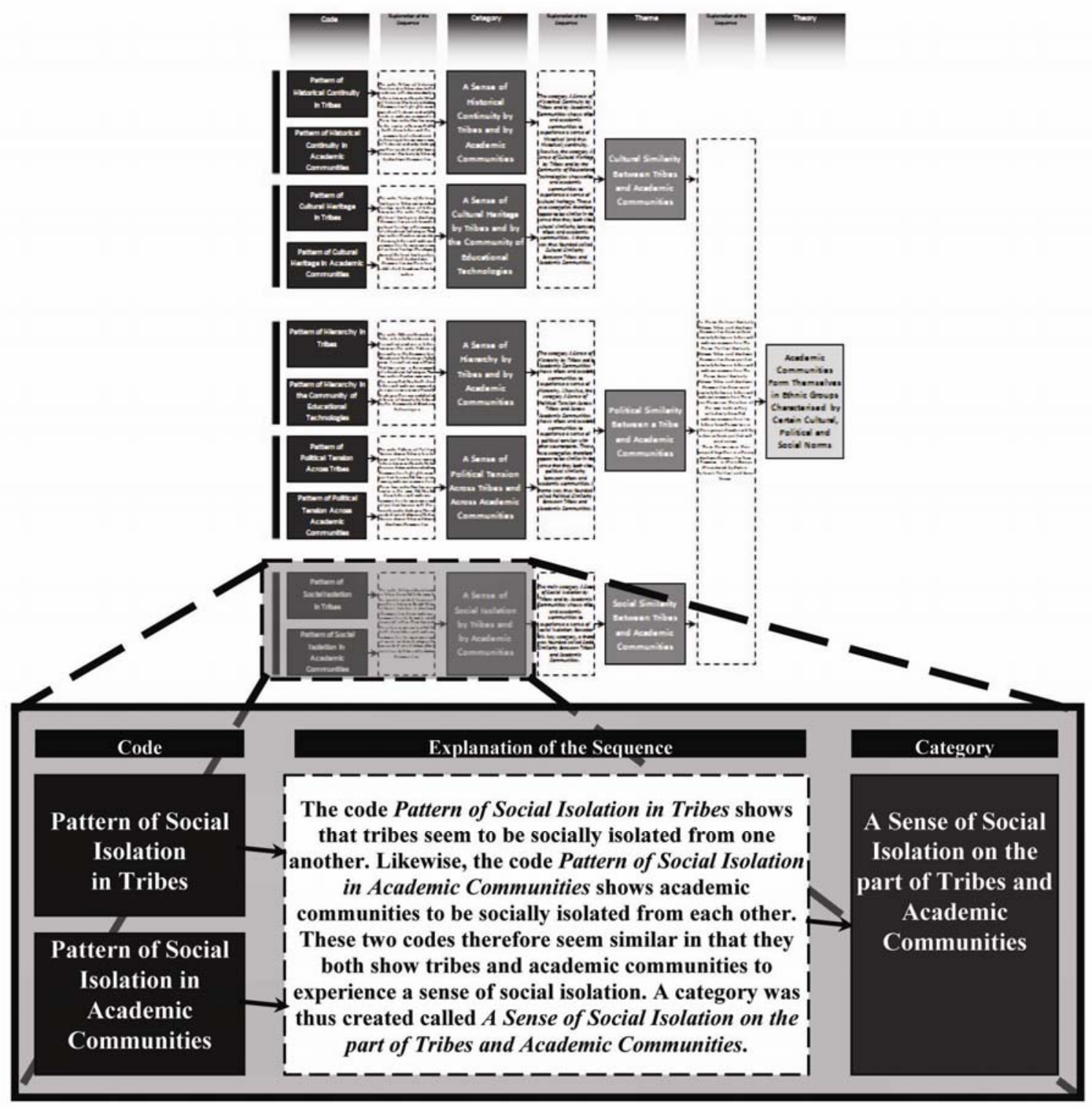

As indicated by the observation of the tribes, a tribe typically appears to present a sense of inter-tribal political fragmentation. This, as noted by some interviewees, seems to be equivalent to the inter- and intra-disciplinary political fragmentation within academic circles, which could be seen through the political tensions between the different disciplinary divisions (or "disciplinary clans," as an interviewee preferred to label them) and between the advocates of different methodological approaches. Some universities use the phrase "disciplinary division" in terms of their organisational structure, and the use of the word "division" here is evidence for the inter-political fragmentation across disciplines. Likewise, some higher education institutions use the term "discipline" to refer to a certain academic domain, and the use of the term "discipline" here reminds us of Foucault's book Discipline and Punish, which talks about prisons and their structure and organisation. One can wonder why certain researchers cite only certain researchers and avoid citing others. Is it because these researchers are "stuck" with these researchers and have a limited scope or, on the other hand, is it because there is some kind of tension and 
conflict between these researchers and those they avoid? One might see personal connections as being influential in the field of educational technologies, with certain keynote speakers but not others being invited to conferences and the like. One might hold the belief that, even with the fact that the peer-reviewing process of articles is double blind, authors can identify their reviewers and likewise reviewers can spot the authors, for various reasons. For example, authors may cite themselves in their articles, use certain words across their articles, be interested in certain aspects of educational technologies, focus on a certain social context and use certain methodological analytical and interpretative approaches, which all help a reviewer to know who the author is.

\section{Concluding Remarks}

The paper has sought to find new ways of characterising how the academic world functions. It has responded to what seems to have been a politically charged reference to the field of educational technologies as a "tribe" in a recent journal article. It has investigated the claim that the international academic community of educational technologies seems to have acted in a "tribal" way, having shaped themselves around tribe-like norms. It has addressed the research question: What are these claimed tribe-like practices that such a community exhibits? This question is answered by qualitatively enquiring into the anthropological norms of tribes and, likewise, into the "anthropological" norms of academic communities. Having analysed the data using the grounded theory approach, three key themes have emerged: Cultural Similarities between Tribes and Academic Communities, Political Similarities between Tribes and Academic Communities and Social Similarities between Tribes and Academic Communities. A reader might say that this article lacks examples and extracts from the data. This criticism sounds fair indeed, but this article is intended to establish a theoretical framework and to hopefully act as a theoretical reference for other researchers. Yet, the insertion of examples and extracts from the raw data would, the author believed, have undermined the aim of the article at presenting theorisation. Besides, it was felt that examples and extracts from the raw data should be presented only in conference papers and should be provided for readers only when requested for use as secondary data.

Having considered the above-mentioned themes collectively with reference to the existing literature, a theoretical proposition can therefore be grounded: that academic communities are similar to tribes in the sense that all, naturally, constitute themselves in ethnic groups characterised by distinct cultural, political and social norms (see the table below). It could be said that tribes and academic communities are similar in the sense that their members belong to a political "institution" (i.e., a tribe or an academic community) but cannot realise that they are politicised or do politics, or at least that their institution has a fundamental political aspect. A reader might wonder how this help academics to think about academia from now on. What follows seeks to address this concern. 
Table 10. Emerging theoretical proposition

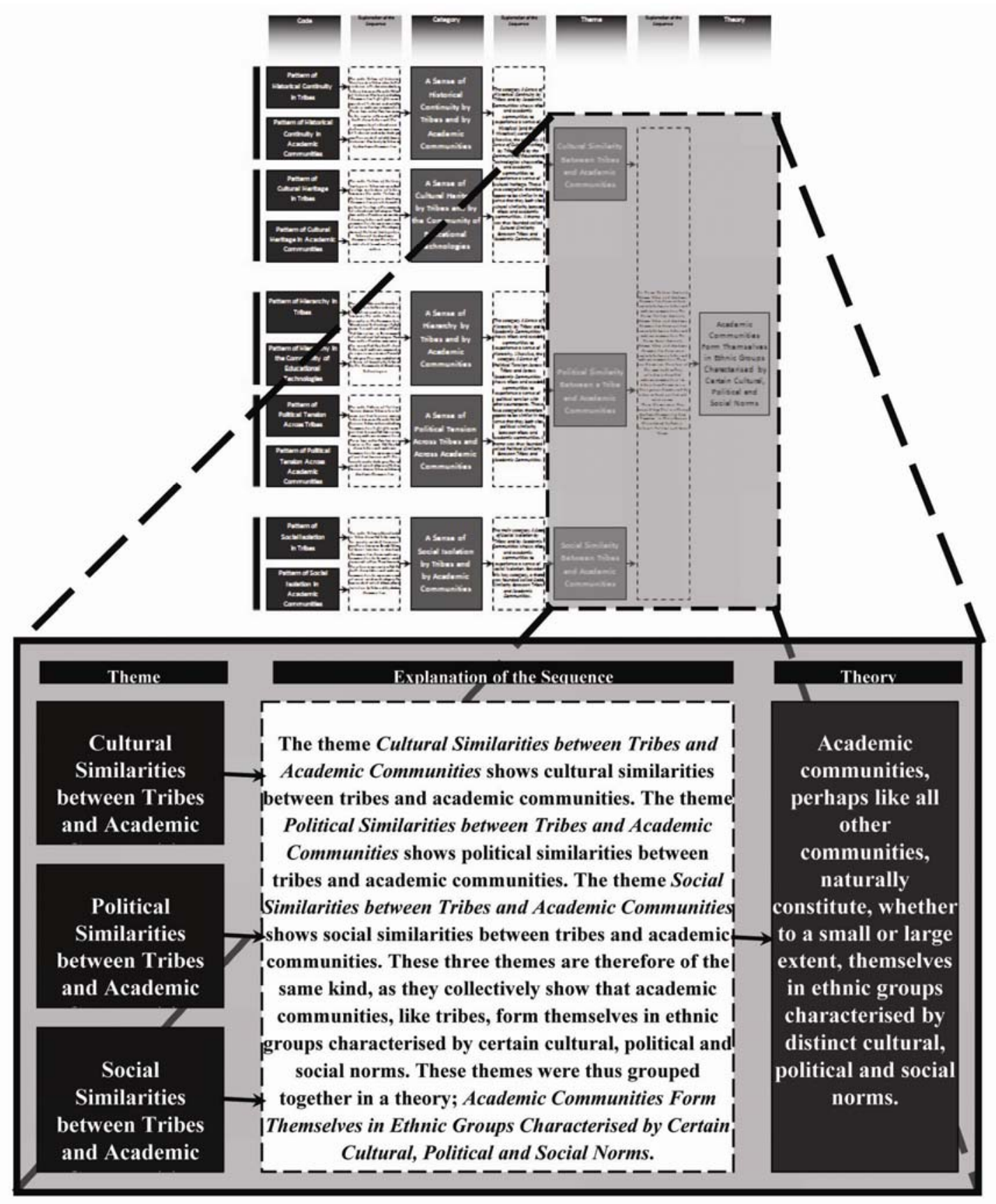

Having considered the emerging theoretical proposition, an overlooked implication is thus that academic communities are, at least partially, culturally, politically and socially different. In implying that, the recommendation therefore is not to seek the elimination of such cultural, political and social differences but rather to foster cross-community cultural, political and social exchange and therefore learning (see also Al Qathami, 2009). Such a recommendation is actually promoted by Saudi culture, which holds the belief that human society necessarily and unavoidably forms itself into different ethnic groups. A complementary belief that is also widespread in Saudi Arabia is that the deliberate creation of human society in different ethnic groups is intended to enable groups to be introduced to one another, to form relationships among themselves and to enhance inter-group exchange. Following these beliefs, the existence of the academic community of educational technologies as an ethnic group different from other communities can be said to merely follow human nature and therefore cannot be avoided. Likewise, the academic community of educational technologies forming itself in an ethnic group should be perceived as being a positive matter. Trowler (University World News, 20 November 2011) 
puts forward the argument that various factors (e.g., digital technologies) have contributed to the "de-tribalisation” (to borrow a phrase from McLuhan, 1994, p. 32) of academic communities and therefore that "the tribes metaphor has probably outlived its usefulness and new metaphors are required” (Trowler, University World News, 20 November 2011, n.p.). Yet, considering the theories discussing the relationship between offline and online settings (e.g., Nip, 2004; Subrahmanyam, 2008; Samin, 2008), one might argue that digital technologies might have not de-tribalised academic communities but rather "e-tribalised" (in the terminology of Kozinets, 1999) them, allowing academic communities to go online and maintain their tribal aspects in the virtual world. One might further argue that digital technologies might have "re-tribalised" (Kozinets, 1999, p. 252) not only academic communities but moreover human society into clusters of affiliation (McLuhan, 1970).

The current study, like any other scholarly enquiry, has limitations, for example in focusing particularly on the negative patterns around which tribes have been formed, thus not leaving as much room for the positive ones. The subject matter of the current study and its findings are provocative, but the hope is that this study is perceived by other researchers as an exploratory one that acts as merely a primitive step towards further investigation. It is, moreover, hoped that researchers increasingly view the "landscape" of educational technologies through the lens of anthropology and, indeed, through the eyes of other disciplines. It must be made clear, with my apologies, that some parts of the article are deliberately worded in a "teasing" way, with the political intention of counter-balancing the existing literature which tends to be formulated in a disciplined charismatic manner.

The current study has lent support to the claim that, although higher education institutions have been seen as places which transfer knowledge and from which people seek expertise, they are, however, weak in applying this knowledge to themselves (Hammond et al., 1992; Cornford \& Pollock, 2003). That is, the article has shown that the academic community of educational technologies has experienced a lack of exposure to other communities, although this community actually promotes the idea that educational technologies should be used to facilitate the integration of one group into other groups and wider society. Thus, although educational technologists stress the role of educational technologies in opening up people to others and wider society, they themselves seem not to have been able to take advantage of what they have marketed to their audience, thus remaining isolated.

The article has shown that the academic culture of educational technologies is tribal in the sense that its interdisciplinary collaboration is limited while its interdisciplinary tension is strong. It seems that this tribal aspect of the educational technology community is an overall phenomenon within academia. That is, although Cohen and March (1974) were writing in the 1970s, their words seem applicable to modern higher education institutions today: "anything that requires the coordinated effort of the organisation in order to start is unlikely to be started, and anything that requires a coordinated effort of the organisation in order to be stopped is unlikely to be stopped” (p. 206). The article has also shown that the academic community of educational technologies is tribal in the sense that it sustains a sense of the historical continuity of its activity and dynamics. Yet one might defend educational technologists, arguing that the concern of such technologists to maintain historical continuity is informed by the interests of the wider academic system in maintaining the historical continuity of its structure and infrastructure. That is, technological innovations in higher education are to be designed "from within the constraints and limitations of the traditional university” (Cornford and Pollock, 2003, p. 36: original emphasis) and the concern is to continue to work with and attempt to "fit [new technological structures] into existing concepts, arrangements and infrastructures” (Cornford \& Pollock, 2003, p. 36). Collis and van der Wende (2002) conclude their international comparative study by suggesting "that higher education institutions do not expect revolutionary change as a result from or related to the use of [information and communications technologies]” (p. 61). This can remind us of the debates around skeuomorphism, whereby the digital has visual properties similar as the physical and whereby new versions of software has the same properties as previous versions (Norman, 1988, 1990; Rodman, 2012).

A political recommendation that could be drawn from the current article is the need for more politically literate researchers who seek to destabilise the tribal aspects of their academic community. The concern of these researchers should be to transform their community into a "civilised" community that is keen to flatten academic hierarchy, promote historical discontinuity, foster interdisciplinary collaboration and encourage cultural, political and social exchange across academic communities. This is, however, not to say that conflict across academic communities should be discouraged, considering the role of conflict, tension and competition in triggering creativity and innovation. That said, conflict could also lead to entrenched power relations distorting the ability of innovative practices to take root (Al Lily, 2012). Hence, the flattening of the hierarchy must be done first before encouraging conflict.

To conclude, it should be remarked that there seems to have actually emerged a new generation of scholars, or 
"trend-setters" as an interviewee called them, who are interested in destabilising the tribal aspects of the educational technology community. For example, Selwyn (2007) promotes the idea of looking at educational technologies from a deliberately questioning perspective. Likewise, McPherson and Whitworth (2008) show educational technologies to be actually a matter of organisational politics. Hope, Oliver and Candappa (Hope, 2007; Oliver \& Candappa, 2003) encourage the idea of viewing educational technologies through the lens of criminology. Yet such scholars are researchers, not political activists, and therefore the spread of their ideas throughout society remains slow, not being well publicised or promoted. Another reason why the spread of such ideas seems slow is that these scholars appear to be critical of academic communities, and therefore the members of these communities might see themselves as being criticised and hence react defensively, resisting their ideas. This is, however, not to say that the ideas of these scholars should not be subject to criticism, as it is surely a natural process for one to both criticise and be criticised. Within such a culture of exchange of criticisms, what should be avoided is defensive criticism, which needs to be replaced with constructive criticism. Policy-makers might, as stated by some interviewees, have thought of such thinkers as revolutionary and seen the writings of these scholars as not being "policy material." Indeed, some research students might, as anticipated by some interviewees, avoid their ideas, seeing them as unconventional and thus feeling concerned that the use of such unconventional ideas to gain academic degrees can be risky considering that "the safest way to gain an academic degree is to stick with academic conventions” (an interviewee).

\section{References}

Adams, H. (1976). The Academic Tribes. New York: Liveright.

Al Lily, A. E. A. (2012). The Role of Educational Technologies in Linking Saudi Male and Female Campuses (Unpublished doctoral dissertation). The University of Oxford.

Al Qathami, A. M. (2009). Al-Qabeelah wa Al-Qabaayel aw Hawayat Mabaad Al-Hadathah "Tribes and Tribism or Identities of Post-Modernisation". Morocco: Al-Dar Al Bayeda.

Al Salem, A. A. (2005). The Impact of the Internet on Saudi Arabian EFL Females' Self-image and Social Attitudes (Unpublished doctoral dissertation). Indiana University of Pennsylvania.

Appignanesi, R., \& Garratt, C. (1995). Postmodernism for Beginners. London: Icon Books.

Apple, M. (2004). Are we wasting money on computers in schools? Educational Policy, 18, 513-522. http://dx.doi.org/10.1177/0895904804265022

Bauman, Z. (1988). Is there a postmodern sociology? Theory, Culture and Society, 5, 217-237. http://dx.doi.org/10.1177/0263276488005002002

Becher, T., \& Trowler, P. (2001). Academic Tribes and Territories: Intellectual Enquiry and the Culture of Disciplines (2nd ed.). Buckingham: Open University Press.

Beteille, A. (1980). On the concept of tribe. International Social Science Journal, 32(4), 825-828.

Caton, S. C. (1990). Peaks of Yemen I Summon: Poetry as Cultural Practice in a North Yemeni Tribe. University of California Press.

Cohen, M. D., \& March, J. G. (1974). Leadership and Ambiguity: The American College President. New York: McGraw Hill.

Collis, B., \& van der Wende, M. (2002). Models of Technology and Change in Higher Education: An International Comparative Survey on the Current and Future Uses of ICT in Higher Education. University of Twente, Enschede: CHEPS.

Cook, P. A. W. (1934). The education of a South African tribe. Juta \& Company, Limited.

Cornford, J., \& Pollock, N. (2003). Putting the University Online: Information, Technology, and Organizational Change. Buckingham: Open University Press.

Dear, M., \& Wolch, J. (1989). How territory shapes social life. In J. Wolch, \& M. Dear (Eds.), The Power of Geography: How Territory Shapes Social Life. London: Unwin Hyman.

Denscombe, M. (2007). The Good Research Guide: For Small-Scale Social Research Projects (3rd ed.). Buckingham: Open University Press.

Duderstadt, J. J., Atkins, D. E., \& Van Houweling, D. (2002). Higher Education in the Digital Age: Technology Issues and Strategies for American Colleges and Universities. Westport, CT: American Council on Education and Praeger. 
Frohnmayer, D. (1988). The New Tribalism. Retrieved from http://www.frohnmayer.uoregon.edu/speeches/newtribalism/

Glaser, B. G., \& Strauss, A. L. (1967). The Discovery of Grounded Theory: Strategies for Qualitative Research. Chicago: Aldine Pub.

Gluckman, M. (1960). Tribalism in Modern British Central Africa. Cahiers d'etudes africaines, 1(1), 55-70. http://dx.doi.org/10.3406/cea.1960.2939

Gluckman, M. (2007). Social beliefs and individual thinking in tribal society. In R. A. Manners, \& D. Kaplan (Eds.), Anthropological Theory. Transaction Publishers.

Graça, J. (2010). Between the Winner's Curse and the Blessings of Vintage (Unpublished master's thesis). Aalborg University.

Gutkind, P. C. W. (Ed.). (1970). The Passing of Tribal Man in Africa (Vol. 10). Brill Archive.

Hammond, N., Gardner, N., Heath, S., Kibby, M., Mayes, T., McAleese, R., ... Trapp, A. (1992). Blocks to the effective use of information technology in higher education. Computers Education, 18, 155-162. http://dx.doi.org/10.1016/0360-1315(92)90049-B

Herr, K., \& Anderson, G. L. (2005). The Action Research Dissertation: A Guide for Students and Faculty. London: Sage.

Holliday, A. R. (2005). Doing and Writing Qualitative Research. London: Sage.

Hope, A. (2007). Risk taking, boundary performance and intentional school internet "misuse”. Discourse, 28(1), 87-99.

Horsman, M., \& Marshall, A. (1994). After the Nation-State: Citizens, Tribalism and the New World Disorder.

Hunter, D. J. (1994). From tribalism to corporatism. Challenging medicine (pp. 1-22).

Husni, A. (2013). Khaberat al nabi alayeh al salat wa al salam betanteem al hayat al khabaleyah qabela al betha (The experience of the Prophet with the organisation of the tribal life before his message). n/a, 9 .

James, P. (2006). Globalism, nationalism, tribalism: Bringing theory back in. London: Sage.

Kast, F., \& Rosenzweig, J. (1979). Organization and Management: A Systems and Contingency Approach (3rd ed.). New York: McGraw-Hill.

Kornel, D. (2006). Tribals and Their Culture: Koya Tribe in Transition. APH Publishing.

Kozinets, R. V. (1999). E-tribalized marketing?: The strategic implications of virtual communities of $\begin{array}{llll}\text { consumption. } \quad \text { European } & \text { Management }\end{array}$ http://dx.doi.org/10.1016/S0263-2373(99)00004-3

Langloh-Parker, K. (1905). The Euahlayi Tribe. A Study of Aboriginal Life in Australia. London.

Lowe, C., Brimah, T., Marsh, P.-A., Minter, W., \& Muyangwa, M. (1997). Talking about “tribe”: Moving from stereotypes to analysis. Africa Policy E-Journal, n/a.

Mafeje, A. (1971). The ideology of tribalism. Journal of Modern African Studies, 9(2), 253-261. http://dx.doi.org/10.1017/S0022278X00024927

Marshall, W. E., \& Pope, G. U. (1873). A Phrenologist Amongst the Todas, Or, The Study of a Primitive Tribe in South India: History, Character, Customs, Religion, Infanticide, Polyandry, Language (Vol. 2). Longman, Green, \& Company.

Marx, K. (1971). Capital. Moscow: Progress Publishers.

McLuhan, M. (1970). Culture is our business. McGraw-Hill.

McLuhan, M. (1994). Understanding Media: The Extensions of Man. MIT press.

McPherson, M., \& Whitworth, A. (2008). Editorial introduction: BJET special issue on best practice or situated action: The organization of technology enhanced learning. British Journal of Educational Technology, 39(3), 411-421. http://dx.doi.org/10.1111/j.1467-8535.2008.00843.x

Mezirow, J. (1990). Conclusion: Toward transformative learning and emancipator education. In J. Mezirow, \& Associates (Eds.), Fostering Critical Reflection in Adulthood: A Guide to Transformative and Emancipatory Learning. San Francisco: Jossey-Bass.

Mezirow, J., \& Associates. (1975). Fostering Critical Reflection in Adulthood: A Guide to Transformative and 
Emancipatory Learning. San Francisco: Jossey-Bass.

Monahan, T. (2004). Just another tool? IT pedagogy and the commodification of education. The Urban Review, 36(4), 271-292. http://dx.doi.org/10.1007/s11256-004-2084-y

Nip, J. Y. (2004). The relationship between online and offline communities: The case of the Queer Sisters. Media, Culture \& Society, 26(3), 409-428. http://dx.doi.org/10.1177/0163443704042262

Norman, D. A. (1988). The Psychology of Everyday Things. New York: Basic Books.

Norman, D. A. (1990). The Design of Everyday Things. New York: Doubleday.

Oliver, C., \& Candappa, M. (2003). Tackling Bullying: Listening to the Views of Children and Young People. Nottingham: Department for Education and Skills.

Pompei, R., Cornaglia, G., Ingianni, A., \& Satta, G. (1990). Use of a novel phosphatase test for simplified identification of species of the tribe Proteeae. Journal of Clinical Microbiology, 28(6), 1214-1218.

Rodman, T. (2012). This is you: Turntable.fm and the digital/physical divide. Technomusicology: A Sandbox Journal, 3(2), n/a.

Samin, N. (2008). Dynamics of Internet use: Saudi youth, religious minorities and tribal communities. Middle East Journal of Culture and Communication, 1(2), 197-215. http://dx.doi.org/10.1163/187398608X335838

Schütz, A. (1944). The stranger: An essay in social psychology. American Journal of Sociology, 49(1944), 499-507. http://dx.doi.org/10.1086/219472

Selwyn, N. (2007). The use of computer technology in university teaching and learning: A critical perspective. Journal of Computer Assisted Learning, 23(2), 83-84. http://dx.doi.org/10.1111/j.1365-2729.2006.00204.x

Selwyn, N. (2010). Looking beyond learning: Notes towards the critical study of educational technology. Journal of Computer Assisted Learning, 26(1), 65-73. http://dx.doi.org/10.1111/j.1365-2729.2009.00338.x

Selwyn, N. (2012). Bursting out of the "ed-tech" bubble. Learning, Media and Technology, 37(4), 331-334. http://dx.doi.org/10.1080/17439884.2012.680212

Subrahmanyam, K., Reich, S. M., Waechter, N., \& Espinoza, G. (2008). Online and offline social networks: Use of social networking sites by emerging adults. Journal of Applied Developmental Psychology, 29(6), 420-433. http://dx.doi.org/10.1016/j.appdev.2008.07.003

Trowler, P., Saunders, M., \& Bamber, R. (Eds.). (2012). Tribes and Territories in the 21st-century: Rethinking the significance of disciplines in higher education. London: Routledge.

Tutchin, J. (1691). The tribe of Levi: A Poem. London: [s.n.]

Vail, L. (Ed.). (1989). The Creation of Tribalism in Southern Africa. America: University of California Press.

\section{Copyrights}

Copyright for this article is retained by the author(s), with first publication rights granted to the journal.

This is an open-access article distributed under the terms and conditions of the Creative Commons Attribution license (http://creativecommons.org/licenses/by/3.0/). 